\title{
Corrigendum to "A Case Study of Mass Transport during the East-West Oscillation of the Asian Summer Monsoon Anticyclone"
}

\author{
Jiali Luo $\mathbb{D}$, Jiayao Song, Hongying Tian, Lei Liu, and Xinlei Liang \\ Key Laboratory for Semi-Arid Climate Change of the Ministry of Education, College of Atmospheric Sciences, \\ Lanzhou University, Lanzhou, China \\ Correspondence should be addressed to Jiali Luo; luojl@lzu.edu.cn \\ Received 26 April 2018; Accepted 8 May 2018; Published 18 July 2018 \\ Copyright (c) 2018 Jiali Luo et al. This is an open access article distributed under the Creative Commons Attribution License, which \\ permits unrestricted use, distribution, and reproduction in any medium, provided the original work is properly cited.
}

In the article titled "A Case Study of Mass Transport during the East-West Oscillation of the Asian Summer Monsoon Anticyclone" [1], there were errors in Section 4 and Section 6 , in the legends of Figures 3, 4, and 7, in which the vertical velocities were stated to be 100 times the actual values, and in the description of Figures 7 and 8.

In Section 4, the text reading "In summary, upward motion was stronger along $30^{\circ} \mathrm{N}$ than along $20^{\circ} \mathrm{N}$ " should be corrected to "In summary, upward motion was stronger along $20^{\circ} \mathrm{N}$ than along $30^{\circ} \mathrm{N}$."

In Section 6, the text reading "But the upward motion was much stronger over $30^{\circ} \mathrm{N}$ than over $20^{\circ} \mathrm{N}$ and much weaker over IP" should be corrected to "But the upward motion was much stronger over $20^{\circ} \mathrm{N}$ than over $30^{\circ} \mathrm{N}$ and much weaker over IP."

The legend of Figure 3 should be corrected as follows:

"Daily maps of MLS CO mixing ratio at $100 \mathrm{hPa}$ (color shading) on (a) Aug 3, (b) Aug 5, (c) Aug 7, (d) Aug 9, (e) Aug 10, and (f) Aug 14, 2016. The thick gray lines are the $600 \mathrm{hPa}$ contour of surface pressure, indicating the location of the Tibetan Plateau (TP). The regions inside of the white contours represent areas with upward transport (vertical velocity less than $-0.01 \mathrm{~Pa} / \mathrm{s}$ ) at $100 \mathrm{hPa}$. The five-pointed star indicates the maximum of CO mixing ratio in the Asian summer monsoon region.

The legend of Figure 4 should be corrected as follows:

"The same as Figure 3, but for MLS CO at $215 \mathrm{hPa}$ and vertical velocity at $200 \mathrm{hPa}$. The vertical velocity contours are $-0.05 \mathrm{~Pa} / \mathrm{s}$."

The legend of Figure 7 should be corrected as follows:
"A pressure-longitude cross section of vertical velocity along $20^{\circ} \mathrm{N}$ on (a) Aug 3, (b) Aug 5, (c) Aug 7, (d) Aug 9, (e) Aug 10, and (f) Aug 14, 2016. Gray shading regions indicate upward. Regions within black contours are strong upward motion regions (contour level is $-0.1 \mathrm{~Pa} / \mathrm{s}$ )."

Additionally, the description of Figures 7(a)-7(f) where the text reading "Vertical velocity $(\mathrm{m} / \mathrm{s})$ " should be corrected to "Vertical velocity $(\mathrm{Pa} / \mathrm{s})$."

The description of Figures 8(a)-8(f) where the text reading "Vertical velocity $(\mathrm{m} / \mathrm{s})$ " should be corrected to "Vertical velocity $(\mathrm{Pa} / \mathrm{s})$."

\section{References}

[1] J. Luo, J. Song, H. Tian, L. Liu, and X. Liang, "A case study of mass transport during the east-west oscillation of the Asian summer monsoon anticyclone," Advances in Meteorology, vol. 2017, Article ID 5174025, 13 pages, 2017. 

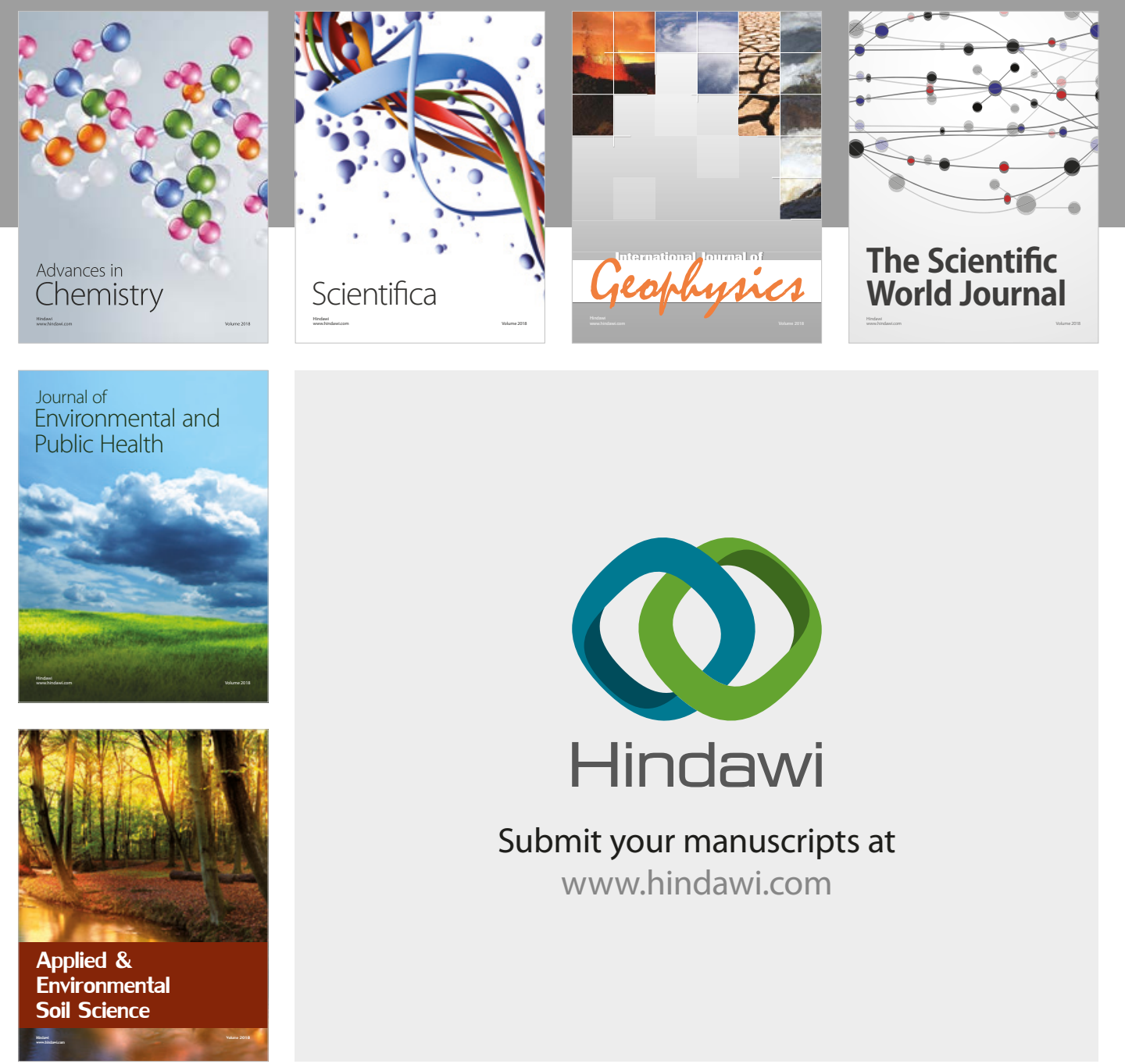

The Scientific

\section{World Journal}
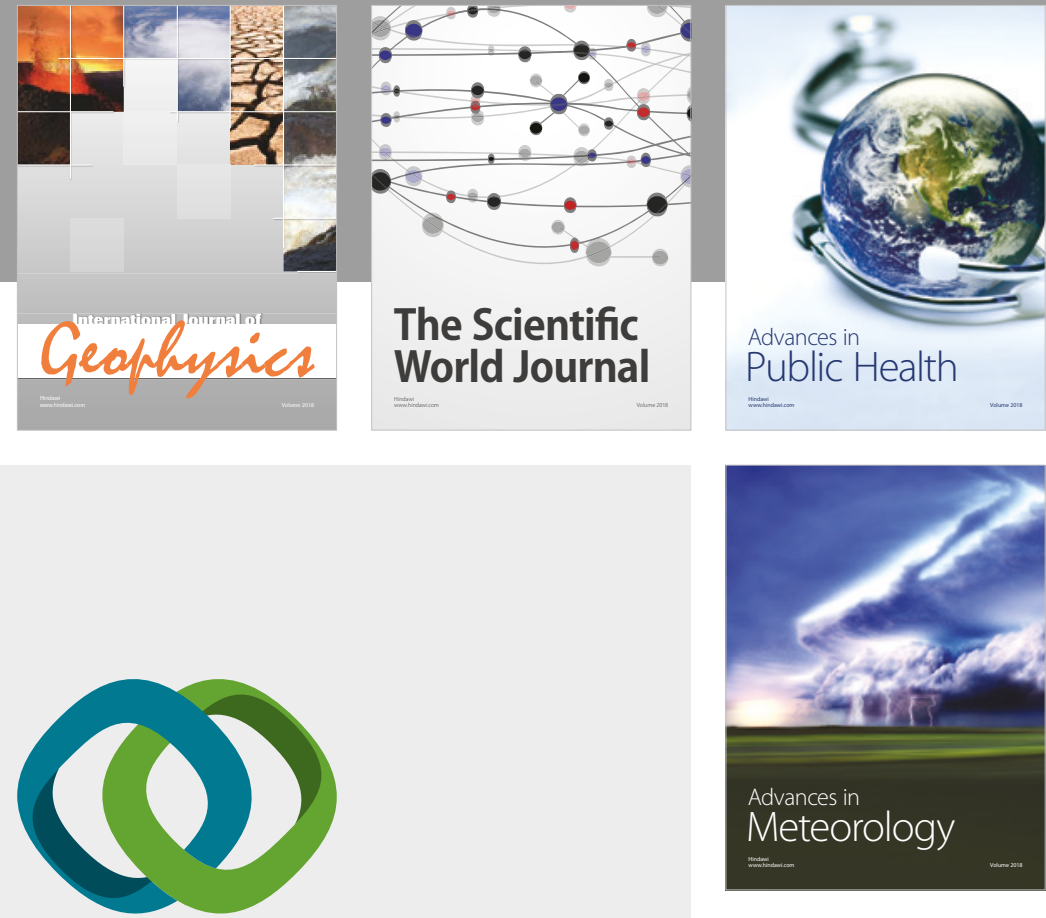

Advan

Public Health

\section{Hindawi}

Submit your manuscripts at

www.hindawi.com
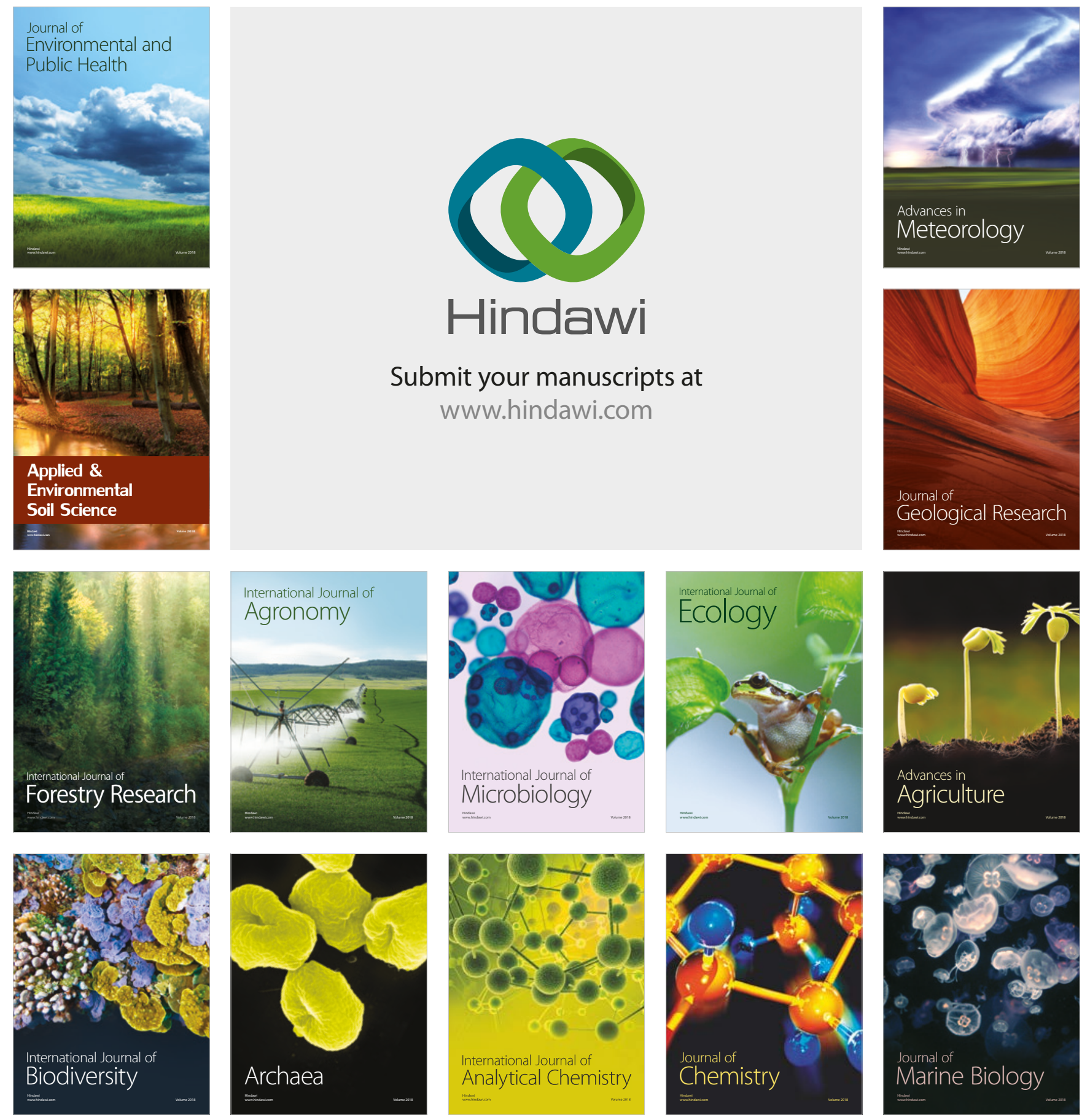